\title{
MASLOW REVISITED: CONSTRUCTING A ROAD MAP OF HUMAN NATURE
}

\author{
Dennis O'Connor \\ Le Moyne College \\ Leodones Yballe \\ Nazareth College of Rochester
}

\begin{abstract}
Given the scope and intent of Maslow's work, the current textbook treatment is wanting. Therefore, an inductive exercise has been created and is offered here to build "the road map of human nature." This age-old, philosophic focus on our true nature has been a way to successfully engage and inspire both our students and our pedagogy. In the spirit of Maslow, the meaning of self-actualization is explored, and the understanding and managing of motivation is embedded into the larger context of leadership, for example, quality, spirituality, ethics, self-awareness, and personal growth.
\end{abstract}

Keywords: Maslow; self-actualization; leadership; pedagogy; hierarchy of needs

A few years ago, we began to reexamine Maslow's works with an appreciative eye: What was the best in his work? What was his vision of human nature? What did he hope to accomplish? How can Maslow help our students in their personal development, and as future managers and leaders? Visiting original sources, scholarly common sense often forgotten (Patzig \& Zimmerman, 1985), led to an eye-opening experience. Long overlooked and forgotten in Maslow's writings, we found a more holistic picture of human nature and a deeper purpose for management and leadership. Our growing excitement was tempered by the limited, and partially inaccurate, portrayal that we saw in current textbooks. This article explains our disappointment and describes an exercise to alternatively convey a richer, more interconnected, and inspiring picture

Authors' Note: Please address correspondence to Dennis O'Connor, Management and Leadership, 1419 Salt Sprints Road, Le Moyne College, Syracuse, NY 13214; e-mail: oconnor@ lemoyne.edu.

JOURNAL OF MANAGEMENT EDUCATION, Vol. XX No. X, Month XXXX xx-xx DOI: $10.1177 / 1052562907307639$

(C) 2007 Organizational Behavior Teaching Society 
of Maslow's work. We offer tips to debrief the activity, to connect to organizations and leadership, and to guide our pedagogy.

\section{Current Treatment}

All Organizational Behavior (OB) textbooks have a motivation chapter that includes a brief section on Maslow's hierarchy of needs, a chart depicting the upward progression of those needs, and a useful set of tips for motivating employees. Two early classics in management writing provided a solid launching point for this wide usage. Douglas McGregor (1960) drew upon Maslow's positive conceptions of human potential and the hierarchy of needs in his management classic, The Human Side of Enterprise. His premise, similar to Schein's (2004) metaphor of culture as an iceberg, was that fundamental, and often unexamined, beliefs and assumptions about human nature lurked below the surface of management practice. McGregor's Theory Y, the set of positive beliefs that people have a range of needs and prefer to grow up and contribute, is basic to all modern innovation in leadership and management. Maslow (1965) also took a keen interest in the application of humanistic psychology beyond one-on-one therapy to larger endeavors (organizations and education) where greater numbers of people could be positively affected.

In spite of the hierarchy's good pedigree and wide recognition, we believe that current textbook treatment suffers in three ways: (a) Maslow is misreported and misunderstood, (b) the positive message is undercut by references to nonvalidating research, and (c) the hierarchy of needs is taken out of context and offered in a too narrow perspective, thereby losing its original intent and spirit.

In 1985, Patzig and Zimmerman pointed out three glaring inaccuracies in standard texts. The leading OB texts reported that Maslow had found in American society that $85 \%$ of physiological needs were met, $70 \%$ of security, $50 \%$ of social needs, and ego and self actualization needs were $40 \%$ and $10 \%$ satisfied, respectively.

The actual passage from Maslow (1943) quoted in their critique stated,

So far, our theoretical discussion may have given the impression that these five sets of needs are somehow in a stepwise, all-or-none relationship to each other. We have spoken in such terms as the following: "If one need is satisfied, then another emerges." This statement might give the false impression that a need must be $100 \%$ satisfied before the next need emerges. In actual fact, most members of society who are normal are partially satisfied in all their basic needs and partially dissatisfied in all their basic needs at the same time. A more realistic description of the hierarchy would be in terms of decreasing percentages of satisfaction as we go up the hierarchy of prepotency. For instance, if I may assign arbitrary figures for the sake of illustration, it is as if the average citizen is satisfied $85 \%$. (pp. 388-389) 
It is clear that these figures were generated by Maslow to simply illustrate a key point, but unfortunately, this error still shows up. Several current texts report these numbers, and one added that "many critics disagree with these figures however, particularly the 10\% figure for self actualization" (Ivancevich \& Matteson, 2002, p. 152). It would seem that textbooks are prone to "viruses" that slip in, promulgate, mutate, and become common knowledge as textbook authors draw upon each other and cross-check their chapters.

The passage just listed also supports our second concern: Maslow's positive message is being unfairly undercut. The textbook presentation of Maslow's hierarchy is typically followed by the caveat that even though many managers still find it intuitively useful, his model is not supported by research. Specifically, research has failed to find evidence that individuals rigidly progress through the hierarchy, that is, that a lower level need must be totally satisfied before the next level can begin to provide motivational force. As one textbook stated, "Scholars have mostly dismissed Maslow's theory . . . because it is much too rigid to explain the dynamic and unstable characteristics of employee needs" (McShane \& Von Glinow, 2005, p. 140). Many textbooks add that Alderfer's ERG theory was developed to overcome these problems with Maslow's theory, because it states more than one need may be activated at the same time. Evidence for this more flexible approach is seen as "encouraging."

Although it is important for students to realize the role of research in providing reliable knowledge, these criticisms are invalidated by the previous quote. The reason that Maslow originally offered the hypothetical example was to illustrate the point that his model is a simplification (as all theories are) and that in ordinary life, behavior is often multiply determined, that is, several needs can and do operate at once. To quote Maslow (1943) again, "Most members of society are partially satisfied in all their basic needs at the same time." Later, he adds, "any motivated behavior ... is a channel through which many basic needs may be simultaneously expressed or satisfied. Typically, an act has more than one motivator" (p. 370).

Maslow understood that there is a very fluid emergence and combination of needs and activity in the rhythm of day-to-day life. The human group survived by bonding together (social needs) to meet the challenges of food and shelter. In fact, right now you, the reader, may have several needs operating simultaneously as you read this (e.g., curiosity, thirst for knowledge, and hunger). It turns out that researchers were right: There is no evidence of a rigid progression through the hierarchy, or that the completion of one level ensures the emergence of the next, but these were never Maslow's theory.

A third major concern about current coverage is the "tool" perspective from which the model is offered. Randolph New, in a conversation with four leading textbook authors (Cameron, Lussier, Ireland, New, \& Robbins 2003), concluded that all four write their books to support a managerial ideology. 
Robbins, who represented the majority of mainstream OB textbook authors, is of particular interest here.

OB texts . . . support a managerial perspective. This reflects the marketbusiness schools. We need to genuflect to the Gods of productivity, efficiency, goals, etc. This strongly influences the dependent variables the researchers choose and the ones that textbook authors use. So we reflect business school values. (p. 714)

As Joan Gallos (1996) noted, "Strong beliefs in technical rationality ... keep us locked into teaching methods and course formats that convey empirically based management truths" (p. 295). Although conveying information, skills, and tips in managing others is important, it begs the bigger questions of values, meaning, and leadership, with which Maslow was deeply concerned. Surgically removing the hierarchy, and adding tips for managing others, violates the larger spirit of Maslow's work. Living systems have integrity. "Dividing an elephant in half does not produce two small elephants" (Senge, 1994, p. 66).

Lacking a larger context, the management approach can play into a manipulative mindset that many students already bring to the topic of motivation. How do you get people to do what you want? In a carrot-and-stick Theory X approach, you give them something. In the hierarchy context, you provide ways for them to get their needs met. That is, of course, part of the answer, but there is much more to it. We need to transcend the limited "tool" perspective of managing others to the larger context of leadership. Both Maslow (1965) and seasoned management educators have taken deep interest in leadership in all its varied dimensions: values and ethics (Lund Dean \& Beggs, 2006), spirituality and meaning (Neal, 1997), emotional intelligence (Brown, 2003), systems thinking and sustainability (Bardoel \& Haslett, 2006; Bradbury, 2003), and self-awareness and personal growth (Bilimoria, 2000a, 2000b; Hunt \& Weintraub, 2004; Schmidt-Wilk, Heaton, \& Steingard, 2000). We can richly connect motivation to these important dimensions of leadership by understanding and teaching Maslow well.

\section{What Did He Actually Say?}

Maslow played a key early role in the humanistic psychology movement, sometimes known as the "third force" in psychology. He felt stifled in an American psychology dominated by behaviorism. He strongly believed that humans are more than billiard balls on the pool table of life. Maslow (1943) begins with a statement that the integrated wholeness of the organism must be one of the foundation stones of motivation theory, that is, motivation (and all other OB topics) cannot be studied only in isolation. Motivation 
must be seen in the context of the whole being, and in connection with other key focuses. Based on his clinical psychology experience, he inductively constructed a rich model of the forces and needs that move us to action.

Over the next several decades, Maslow became increasingly intrigued by what he eventually labeled the "farther reaches of human nature" (Maslow, 1971). He sought to build an appreciative understanding of human beings at their best. In contrast with the preoccupation of Freudian psychopathology, this "psychology of the higher life" was to attend to the question "of what the human being should grow toward" (Maslow, 1964, p. 7). He interviewed folks who had been identified as great people and found that they had somehow become themselves more fully. He began to spell out in more detail the processes and character of self-actualization.

In Maslow's view, self-actualization is not an endpoint but rather an ongoing process that involves dozens of little growth choices that entail risk and require courage. He noted that it was a difficult path to take and often puts us at odds with surrounding people and norms. He also found that selfactualizing people were deeply committed in action to core values that look very similar to those put forward in all major religious traditions. These "being-values" are simple yet difficult to fully embody in the everyday challenges of life—-for example, truth, justice, goodness, beauty, order, simplicity, and meaning or purposefulness.

He observed that self-actualizers were attuned to their own unique biological nature (talents, likes, tastes, etc.) and had a unique, intangible spiritual nature, an interconnected combination of being-values and purpose. He saw these values as "meta-motivators." For example, individuals might be moved to seek justice in the world as well as do justice to their own inner voice or truth. In general, they seek to put things right and to do it the right way. To a person, the self-actualizers were deeply engaged with their immediate worlds. They also were much more likely to report peak, transcendent experiences that helped them see beyond the immediate and develop a spiritual focus. They were "called" to act, and they responded.

We see that there are several identifiable and distinct dimensions to selfactualization in Maslow's writings: the unique self, peak experience and transcendence, spirituality and meaning, and the aesthetic-creative element. Although these dimensions were never fully sorted out, Maslow had begun to posit self-transcendence as the highest need (Koltko-Rivera, 2006.) He helped begin what some have called the "fourth force": exploring the role transcendence of self and spirituality in personal psychology. We agree that we need to find our unique true self and to discover that is part of a greater whole still. Many joined him in this quest, and in 1969, he helped to establish the Journal of Transpersonal Psychology. Others have since taken up this challenging work in the organizational realm by clarifying the critical role of spirituality and meaning in the workplace and leadership. Like Jung, 
the sheer breadth and significance of the connections Maslow made were an important launching point for thinkers of all types.

Finally, Maslow (1965) was also one of a small group of groundbreakers who connected a positive psychology of people to the practical challenge of management and productivity. He saw management and education as potential arenas to reach more people than the one-on-one approach of traditional therapy. He struggled to understand humanity at its best and sought to create a positive psychology and a positive vision for both the individual and the leader. His broad conception of leadership and collaboration is the place to situate our understanding of motivation.

In the context of OB pedagogy, as we continue to seek newer heights of teaching excellence in the service of developing the whole person (Bowen, 1980; Boyatzis \& McLeod, 2001; International Commission on the Apostolate of Jesuit Education, 1986), we are convinced that Maslow has much to offer beyond a simple tool. We need to explore what his work can tell us about one's inner desire and hunger for peak performance, creativity, ethics, values, and meaning, and the interconnections of all these processes in the context of management and leadership. We have created an exercise that we believe helps us get to the deeper values and hopes that we see in Maslow's writings.

\section{AN EXERCISE TO INDUCTIVELY CONSTRUCT A ROAD MAP OF HUMAN NATURE}

Introduction. Much pedagogy is dominated by a deductive approach to knowledge. In the interests of efficiency, key findings and models are presented in neat packages. When this approach is paired with exams, "Tell me what's important" becomes a common refrain from students. In contrast, this exercise uses an inductive, discovery method, which parallels Maslow's original approach, and grounds the inquiry into motivation in the students' own experiences. Although some students prefer a compact presentation of models, the intrinsic interest of certain questions will slowly hook most others: What is human nature? What moves you to act? What do you really need? What do you want? Why do you want? What is missing for you? What is already in you?

Priming the pump. The topic is motivation, and a key question is what moves us to act. We wonder out loud about why people are really here, right now, in this room. What was the motive force that brought you here? We ask them to rate from 1 to 10 their levels of energy, satisfaction, and productivity over the last week. We also ask them to recall two moments of best performance and two experiences of real satisfaction in the last couple of weeks. This brief appreciative exercise (Yballe \& O'Connor, 2000) helps to give depth to the session and to weight the focus toward the best of what we can 
be, consistent with the spirit of Maslow. After we share a brief definition of needs as the tension we experience that drives us to act, we suggest it might be quite useful to have the complete, everything-you-wanted-to-know "road map" of human needs and motivations. We further submit that this big picture would not only be great to grasp the complex dynamics at work but also a tremendous aid to better understand our own experience and all our day-to-day interpersonal and group situations.

Small-group brainstorm. After offering a couple examples of needs, we begin the work of constructing a "road map of human nature." We have found that reframing motivation in this larger and more meaningful context tends to hook both the students' and the instructor's imagination and hence result in more enthusiasm and creativity. We ask our newly formed classproject teams to take a crack at brainstorming a written list of needs. "We want any and all that you've ever experienced, seen, or heard about!"

Brainstorming is fun work, and a list of needs is an easy success for groups in an early stage of development. It is also more engaging for them to get in touch with their own life experience than listening to a description of the list of five human needs, à la the Maslow chart. Right in the room, there are hundreds of years of human experience to draw upon in building a rich, experientially grounded map! In fact, we have found that students are usually able to generate $90 \%$ of almost any topic that we've asked them to brainstorm, for example, management skills, qualities of an ideal, effective group, sources of differing perception, sources of stress, and so on. As they work, we go around to interact with the groups, giving a nudge or two, and reminding them that brainstorming that produces nothing funny or truly dumb is not good brainstorming! "Put down everything, and anything. Censor later." (Another variation that takes slightly longer is to ask small groups to create collages of images from old magazines that reveal the driving forces that they feel in themselves or that "catch their eye" as something important about human nature and motivation.)

Reporting and debriefing. After a short time, we title the board "THE ROAD MAP OF HUMAN NATURE" and ask small groups to report out. As we begin to "simply record" three or four items per group, we unobtrusively organize the data higher and lower on the board without letting on that we are following Maslow's hierarchy. There is usually a dazzling array of needs. Many items, like education or a new car, could go in several places, so we ask for an explanation of why that is a need. Some items we put to the left of the board to deal with later (money, sex) and others in a "not sure" area to the right. After they exhaust their lists, we ask if any other ideas have come to mind. Finally, we conclude, "So, this is it, the total range of human needs? Everything you've always wanted to know? . . Is there anything else, in any time or place that anyone might have needed?" 
In this process of generating and reporting ideas, group members learn to appreciate and trust their own and others' resources while we are free to function as a resource in helping to label and organize the output, and then to link and integrate it to other course topics and themes. They feel competent, and we look smart.

With so much material to work through, the options and order are really a matter of course goals, personal preferences, and spur-of-the-moment insights. We start by marveling at the richness of expression, noting the dozens of items that comprise our road map. We then draw some lines to separate the items according to the levels in Maslow's model and inquire if anyone noticed that their responses had been mapped into Maslow's hierarchy.

We briefly describe the biological and emotional forces that make the lower needs prepotent. If you are running out of air, all other concerns are quickly forgotten! As we find ways to handle the physiological needs, they lose their intensity, and attention can turn to other concerns, such as the safety and security needs. We all need some order and stability in our lives: Will I eat tomorrow? Am I safe from physical danger? Will I be OK? Such needs can also become very intense and drive out other concerns for the time being. With the third level, social needs, we point out that we are, in our deepest roots, social beings. It was the tribe that survived. Everyone in the room is and always has been complexly interconnected with others. We are a physical being first, but as infants, we soon begin bonding, and our social nature becomes quite apparent. We bond with others throughout life, and we need friends, family, inclusion, acceptance, and unconditional love.

The fourth level focuses on the need for self-esteem. Our basic nature is also individual. With language, we begin to form a personal identity, which is always rooted in a social matrix of a particular time and place. We are separate from others and existentially alone. As we feel secure and confident in our group memberships, our attention can turn to standing out from the group. We need inclusion, but we also seek to stand apart and influence others. Good self-esteem is "soundly based on real capacity, achievement, and respect from others. ... Satisfaction of self esteem needs leads to feelings of self confidence, worth, strength, capability, and adequacy of being useful and necessary in the world" (Maslow, 1943, p. 382).

Listing esteem needs as "higher" has caused a certain amount of crosscultural debate. The word higher tends to connote better, but we have not found any evidence that Maslow judged someone motivated predominantly by self-esteem needs (preferred by individualistic cultures) as better than someone at the social need level (preferred by cultures that favor collectivism). He simply saw "social needs" as more basic, or pre-potent. Life is a constant unveiling of self. Certain aspects of our nature come forward first, and others are brought to play later. Furthermore, every culture shapes both 
social and individual nature together. Relative to their differing circumstances and history, each develops unique configurations of behavior and values that shape the expression of needs and puts different emphasis and accent on each of the basic needs. Hofstede (1977) found that American society overemphasizes individualism. Is this a better, purer, higher, more effective motivation than a collective emphasis? Maslow would conclude that functioning chiefly at either the social or self-esteem levels is dangerously incomplete and unhealthy. For an extended psychodynamic treatment of each need-level as an organizing, but incomplete psychology of work, see Schwartz (1983).

At this point, we pause and revisit our initial musing about why people are here. We try to place the reasons in the hierarchy and speculate as to the power of various motivations to bring about excellent performance at school and work. We demonstrate that it is possible to use this model to reflect on and analyze one's performance and suggest that more data be gathered by examining what other needs have come into play during the last week. What need-satisfying behavior has been in the service of your goals? What has been distracting? How might a diary or journal be helpful in building deeper awareness? We give small groups a few minutes to share some examples of good performance and to make their best guess at the underlying motivations. We point out that there is a story or pattern that underlies most of our best performances. It is worth clarifying and developing this storyline in contrast to the ones associated with mediocre performance (Adams, 1986).

Two items, money and sex, are usually of great interest and central to understanding motivation. We sometimes play devil's advocate to those who argue money is the most powerful and effective motivator. How effective is money for you? Would a promise of $\$ 100$ at the end of the semester help you study today and tomorrow? How so? Data on happiness tell us that families who make $\$ 100,000$ are no happier than those who make $\$ 50,000$. Can this be true?

"Sex" is perhaps most amusing, when the class fails to mention it. We announce, "We have exciting news, our road map is incomplete, and you have something really good to look forward to!" This can lead nicely into discussion about what is our "true" nature. Can all motivation be reduced to the biological drives of sex and aggression, à la Freud? Or do we have a spiritual nature (as intangible as love or ego) that is just as real in its effects and that "pulls" us to act (à la Jung, Maslow, and all major religions)? What is the relationship between these two realities, biological and spiritual? Are they necessarily opposed and in conflict? Can we celebrate both together? 


\section{MASLOW, THE SELF, AND OTHERS: A LECTURETTE ON SELF-ACTUALIZING}

The question of our intangible nature leads us to look at "self-actualization," and we need to do some digging to establish what this really means. Generally, only a few of the reported needs (e.g., spiritual, religion, meaning, challenge) qualify for this category. The road map needs more work; it is still fuzzy and incomplete. We ask how many have heard the term self-actualization and how many can define it. Although some have heard this term, rarely are students able to expound on its meaning. Making your self "actual" is the most basic meaning. Although it sounds simple enough, it is not easy according to Maslow. "We must be very careful to imply only that the higher life is in principle possible, and never that it is probable, or likely, or easy to attain" (Maslow, 1965, p. 314). So how do we become more real? We offer a few of Maslow's suggestions for behaviors leading to self-actualization:

Self-actualizing and self. Maslow provides some ideas on how one can focus on internal growth.

1. See life as a series of choices. "Making the growth choice, rather than the fear choice a dozen times a day is to move a dozen times a day to self-actualization" (Maslow, 1971, p. 44). Life is precious. Become curious and fascinated with choice and outcome. Experiment, reflect, refine.

2. Be honest with yourself, take responsibility, be fair, and be true to one's inner voice are powerful strategies. "What tastes good to you, what do you believe is right?" These simple behaviors slowly root one in the solid foundation of one's own unique nature. They eventually provide the courage to be different, to stand up for the self and for one's convictions, and to sustain a difficult mission in the face of external pressure for conformity and personal needs for safety, acceptance, and status.

3. Have "something to admire, to sacrifice" oneself for, "to surrender to, to die for" (Maslow, 1964, p. 42). You are on solid ground in the self-actualizing journey when searching for something greater than the limited, individualized self. The journey progresses more deeply when you put yourself in the service of that which is greater than yourself-such as country, faith, or human dignity.

4. Be open to the eternal, the divine, the noble, the sacred, and the poetic. Revisit your religious tradition with a new eye; try meditation (Alexander, Rainforth, \& Gelderloos, 1991); notice your peak experiences. The artist's route is to open the self and allow the larger "force" to express itself; thus transcending the narrow limits of a small conscious mind directing all activity, and greatly expanding creative power. Maslow saw the transcendent aspect of peak experiences as an important element in learning to appreciate the eternal and the sacred. Developing and clarifying our spiritual side and identifying with a greater purpose extends and strengthens the self in a turbulent world (Schmidt-Wilks, Heaton, \& Steingard, 2000). We could think of these activities as disciplines to build "spiritual intelligence." Become a spiritual being on a human journey. 
Self-actualizing and others. Maslow also has advice for self-actualizing when being with others.

1. Be honest with others, be not afraid of the truth. Truthfulness often requires courage, enhances integrity, and buttresses credibility. The honest person is in a greater position to effectively serve others - to coach and mentor, to provide fraternal correction, to provide feedback that the other can hear and use, or to provide solace and comfort to those who are confused or distressed. "All profoundly serious, ultimately-concerned people of good will can travel together for a very long distance" (Maslow, 1964, p. 54).

2. Profess your values before others. "Trying to be value-free, trying to be purely technological (means without ends) . . . all these are value confusions, philosophical and axiological failures. . . . And inevitably, they breed all the value pathologies" (Maslow, 1964, p. 51).

3. Help others to be self-actualizers and develop their capacity for peak experiences. It is best to assume that "non-peakers" are really "weak" peakers rather than people who lack the capacity all together (Maslow, 1964, p. 86). As others begin to see themselves as having had peak experiences, it is possible for them to understand and identify with the great "peakers."

Finding and becoming one's self is critical work, but the idea has been coopted and misinterpreted by ubiquitous marketers (e.g., "It's all about me!"). We pointedly note that Maslow found that self-actualizers are not self-centered, but are quite the opposite. To a person, self-actualizers possess a contributory mindset as opposed to a comparative (what-do-I-get) approach. These individuals extended themselves and sought to improve the well-being of their groups and community. They looked inward and outward. Their choices in what to do and how to do it were guided by their understanding of their own unique talents, preferences, values, and meaning. Their experience of self is extended to include the wider world.

To further deepen the understanding of the values dimension of selfactualization, we ask groups to take a few minutes to list some of the core values they endorse or identified as important in religious training. Classes are quite amazed when we compare their lists to the being-values that were integral in the lives of those identified as self-actualizing: honesty, truth, beauty, justice, goodness, wholeness, simplicity, meaning, and so on (Maslow, 1965, chap. 23). We ask, "Don't we need these? Why aren't they on the map?! (They seldom are, by the way.) Can you imagine a world (or an organization) without such qualities, where everything is gray, tarnished, and ugly?"

Maslow (1971) argued that a spiritual sickness, an anomie, results when these intangible being-values are not present in one's life or in one's community. Our spiritual nature has its own set of unique requirements. It is as fundamental and real as our biological nature. How much energy do we invest in creating beauty, truth, goodness, dignity, meaning, and justice on a day-to-day basis? Why not imagine our lives with more of these qualities in place? 
We believe that there is a cascade of positive consequences in the selfactualization process that are antidotes to the powerful forces of pop culture and bureaucratic life that keep so many of us operating in a deficiency mode. Young people, at any particular moment, find themselves in a vast sea of images and stories of deficit, weakness, separation, and vulnerability, seemingly best resolved through greed, consumption, and cheap thrills (Vaill, 1989). In such a "pursuit of happiness," the bulk of conscious attention and action becomes overfocused on security, social, and ego needs and is fundamentally unsustainable.

Of course, self-actualizers also have basic needs. They eat and will be hungry again tomorrow. They need security and love and esteem like everyone else. That is our collective human nature. The difference is that the pursuit of their basic needs is organized, aligned, elevated, and sublimated by meaning and purpose, which are rooted in a truer sense of one's values, inclinations, and talents as well as experience with and connection to the "greater self." Such perspective helps to moderate the immediacy and discomfort of lower order deprivations. The self-actualizer is more inner directed, delaying gratification until the right moment. Through experiment and reflection, satisfying basic needs becomes an integrated, consciously managed aspect of a whole life and is not compulsive or desperate, or dominating of all other concerns. A paradigm shift takes place: You become a person who has needs, not a needy person.

The individual, like a culture, must solve the challenges of external adaptation and internal integration. Only the individual is equipped to meet his or her challenges in an optimum way. We use the concept of sustainable development (Bradbury, 2003) to suggest that the process of self-actualization is the core of sustainable happiness: to uncover one's unique self as a foundation to take charge of one's own growth, to struggle with the meaning of existence, and to reintegrate one's various talents, natures, and values. This, we believe, is also the path of leadership.

\section{EXTENDING MASLOW TO ORGANIZATIONS AND LEADERSHIP}

Maslow and self-actualization speak directly to critical clusters of topics in current leadership writing and pedagogy: knowing oneself, personal mastery, and emotional intelligence (Bennis, 1989; Boyatzis, 1994; Drucker, 1999; Dupree, 1990; Goleman, 1997; Senge, 1990); values, meaning, spirituality, and ethics (Bolman \& Deal, 2001; Daniels, Franz, \& Wong, 2000; Ethics Education Task Force, 2004; Ferris, 2002; Tischler, 2000; Vaill, 1989); and quality and peak performance (Deming, 2000; Walton, 1988). Similar to the way that the overarching process of self-actualization reshapes and guides the meeting of lower order needs, the wider context of leadership helps us better understand motivation and use the tools of management. "Good teachers ... 
are able to weave a complex web of connections among themselves, the subject, and the student" (Palmer, 1998, p. 11). There are endless ways to make these connections. We offer a few examples and thoughts, but it is ultimately up to each professor to find personally meaningful ways to illuminate the rich connections to leadership.

We usually begin the final discussion by rhetorically asking what the road map of human nature means for leadership. We begin discussion with a need that we save for the end: QUALITY. Quality, the key focus of the biggest management trend ever, has yet to turn up in any group's brainstorm! This is particularly ironic with MBA students, because many have been exposed to Total Quality Management programs. Do we have a need for quality? Do others? What is the basis of our need for quality? How close to the surface is it? How do leaders make it a key concern for all? To build "quality" into your life, what steps would you need to take specifically? What systems of management, what culture, what leadership will result in quality?

Japanese organizations transcended the false dichotomy of increased costs versus quality, by taking a longer term view. They discovered that an intense focus on quality eventually led to innovations in the processes of work. Costs decreased and quality rose. They demonstrated that quality is a product of a connected, integrated work culture that strives to constantly improve, rather than a series of quick fixes. In a similar way, when trying to reconcile the needs of the individual and the needs of the organization, Maslow (1965) argued that the ultimate goals of the organization, the individual, and the society are not at odds but actually coincide in the long term. The best leaders see the interconnections, transcend the seeming dilemmas, and seek to create a synergy and alignment between the needs and goals of all three. This isn't easy, of course. It requires, among other things, a deep understanding of the full road map and the farther reaches of human nature.

Maslow (1965) firmly believed that leadership should be in the service of the being-values: putting things right, deepening purpose, making things truer, more beautiful, and so on. The good leader provides purposes and goals that are worth caring about and works to craft a spiritual foundation of meaning (Bolman \& Deal, 2001). He or she can appreciate and work with others' religious and spiritual practices (Pielstick, 2005).

With rising expectations for ethical conduct and education, Maslow allows - no, requires - us to raise questions of values. Lund Dean and Beggs (2006) found that most business faculty believe "ethics is a values-driven and internal construct, but teach using compliance-driven and external methods" (p. 40). Maslow's positive vision of the role of the being-values in leadership provides an internal context to situate these compliance and critical analysis approaches. This positive vision helps practitioners and students shore up ethical goals that are too often subject to erosion in competing with the short-term bottom line (Bardoel \& Haslett, 2006), particularly when students perceive a double corporate standard (Rynes, Quinn Trank, Lawson, \& Ilies, 2003). 
We must challenge the assumption that good ethics costs the company money (Jackson, 2006). Similar to a long-term focus on quality, a beingvalues focus is an effective leadership strategy. It provides the leader with the ability to more easily identify with wider concerns. He or she is better able to find common ground with others to build interdependence and generate creative dialogue rather than fighting over a fixed sum, and mired in life-is-a-jungle, and your-loss-is-my-gain.

Influence, power, creative ideas, and love are not fixed quantities. Unlike fixed tangible resources on which so much business logic and procedure are based, we can generate more of these critical but intangible qualities through our interactions and leadership. We can negate each other's influence so none exists, or we can extend a powerful joint influence on unfolding events. If I share an idea with the group, I still have my idea, and together we can build even more. Such synergy is more holistic and based in mutual interdependence. It transcends the selfish-unselfish dichotomy. It is "an actual perception of a higher truth" (Maslow, 1965, p. 97) and the best bet to energize sustainable high performance.

It is clear that leadership, even on the small scale of student group projects, is a challenging endeavor. The student must go beyond managing others to also managing oneself in the process of leadership (O'Connor \& Yballe, 2007). It should come as no surprise that sustainable leadership requires reflection, self-confrontation, and learning. Self-actualization is essential to strengthen and deepen the internal anchors needed to persevere in the face of unprecedented turbulence and uncertainty. We explore this connection of self-actualization and leadership to conclude the exercise but also throughout the course.

One last caveat: Management professors are continually faced with difficult decisions of breadth versus depth. We believe the wholeness of the road map and the rich connections of Maslow to leadership provide a memorable and sufficient framework to address other theories and models of motivation that the reader finds important. The road map activity allows the professor to weave in other views on the spot or provide foreshadowing for following sessions.

\section{Conclusion: What Would Maslow Have Us Do?}

The road map exercise clearly brings to light the multiple dimensions of our nature: physical, social, individual, and spiritual. At any moment, and across a lifetime, we are driven and pulled by many different and interconnected needs. Each of these dimensions is real, is essential, and requires attention for health and wholeness. Maslow offers a rich scheme for understanding ourselves, others, and the leadership situation (see Table 1). 
TABLE 1

Benefits and Challenges in the Road Map of Human Nature

\begin{tabular}{|c|c|c|}
\hline People & Benefits & Challenges \\
\hline Students & $\begin{array}{l}\text { Richer, multidimensional model of } \\
\text { human nature } \\
\text { Exposure to positive vision of } \\
\text { personal growth and leadership } \\
\text { Connections to a wide range of } \\
\text { leadership focuses: values, } \\
\text { spirituality, ethics, emotional } \\
\text { intelligence, sustainability } \\
\text { Frame to understand current } \\
\text { experience at work and in } \\
\text { relationship } \\
\text { Tips to pursue self-actualization } \\
\text { Experience with inductive theory } \\
\text { building } \\
\text { Experience with Appreciative } \\
\text { Inquiry (bring out and build on } \\
\text { the best) }\end{array}$ & $\begin{array}{l}\text { Take self-actualization seriously. } \\
\text { Get on the path of leadership. } \\
\text { Examine and expand own } \\
\text { performance and motivation. } \\
\text { Commit to difficult but satisfying } \\
\text { work of finding self, finding } \\
\text { calling, and finding purpose. }\end{array}$ \\
\hline Professors & $\begin{array}{l}\text { All the above } \\
\text { Puts the care of the individual } \\
\text { student and personal growth } \\
\text { front and center. } \\
\text { Practice with facilitative role as } \\
\text { resource in inductive and } \\
\text { appreciative processes. } \\
\text { Enriches our task and supports } \\
\text { deeper, more satisfying meaning } \\
\text { for our work. }\end{array}$ & $\begin{array}{l}\text { All the above } \\
\text { Create the context of values and } \\
\text { leadership, and make the rich } \\
\text { interconnections between topics, } \\
\text { particularly when not established } \\
\text { in the supporting texts. } \\
\text { Create assignments and activities } \\
\text { that focus on integration of } \\
\text { theory, self, and action. } \\
\text { Educate for personal growth. } \\
\text { Revisit purpose of course, design of } \\
\text { sessions. } \\
\text { Clarify role of teaching in the context } \\
\text { of one's own purpose and growth. }\end{array}$ \\
\hline
\end{tabular}

Maslow (1965) realized that we need theories of leadership and motivation adequate to the tasks of modern organizations. His thinking has provided a firm foundation not only for many modern leadership theorists but also for broad cross-fertilizations of philosophy, systems thinking, and humanistic psychology, for example, Transpersonal and Integral Psychology (Wilber, 1996). Maslow (1971) railed against the "influence and ubiquity of stupidly limited theories of motivation all over the world" (p. 310), for example, cause-effect behaviorism, Freudian reductionism of human life to only biological drives, blank-slate sociological models, and the materialistic, rational-economic models that underlie so much of business education. "We must say harshly of the 'science' of economics that it is generally the 
skilled, technological application of a totally false theory of human needs and values, a theory which recognizes only the existence of lower or material needs" (p. 310).

Our current textbooks acknowledge that employees are valuable assets in a globally competitive environment, but this is not enough. They are not employees or assets; they are people (Drucker, 2002). The people "problem" in organizations is unstructured and fraught with uncertainty. The more structured and tangible technical considerations of business, because they are more concrete and readily accessible, will seem more compelling and draw the most energy and resources. The technical system is, in a sense, prepotent. Too often the "valuable assets" or the social system is an afterthought to which "programs" are applied.

A subtler difficulty with the utilitarian, valuable asset approach is illustrated by the fate of the retired racehorse. The sticky problem of "what have you done for me lately" arises. What happens when I become less "valuable" and who is to say when I'm no longer valuable? The social glue of commitment is eventually weakened.

The mindsets and methods appropriate to the accounting and managing of assets and numbers fall pitifully short, when we need people and teams to operate at their creative best at a world-class level. It's not enough to provide only tools to manage others as assets. Although it is important to understand our place in a turbulent world and the skills needed to thrive (O'Connor, 2001), Maslow would also have us (as pedagogical leaders) set students on the path of leadership, for example, increasing self-awareness and the capacity for self discovery (O'Neil \& Hopkins, 2002), deepening one's knowledge and curiosity about human nature, and seeking and connecting to the broader purposes and goals of life and work (Bolman \& Deal, 2001). For all topics in OB, Maslow requires us to establish an explicit background of values and leadership. The path of leadership becomes the evolving, lifelong context for the collecting and using of management tools, and the basis for joining with others in collaborative activity at the highest levels of performance and creativity.

As professors, we have a role as coaches (O'Neil \& Hopkins, 2002) in our students' being and becoming: extending a hand at the elbow, providing an imperceptible nudge, creating a climate of freedom and dignity, asking deep questions, challenging values, and calling for reflection. And our pedagogy must be appreciative (Yballe \& O'Connor, 2004), helping our students to be aware of their peak experiences and best moments. "There is a kind of I-thou communication of intimates, of friends ... which then enables others to see and appreciate the great artists and the great leaders" (Maslow, 1964, p. 87). Our task is to help students become aware that they can have experiences of self-actualizing and build on those experiences as a basis for a satisfying life and good leadership. We want students to better use the 
knowledge and tools they gain, and so we must also provide a positive and sustainable vision of leadership and life: the challenge and joy of the trip, collaborative working as if the future mattered, commitment to core values, dedication to a higher purpose. It's "the heart's longing to be connected to the largeness of life" (Palmer, 1998, p. 5).

Finally, the OB professor must also take his or her own development as seriously as that of others (Bilimoria, 2000c). As Palmer (1998) cogently argued, we teach who we are, "knowing my students and my subject depends heavily on self-knowledge" (p. 2). This is particularly true for OB and leadership. Venturing onto the path of leadership and self-discovery more intimately acquaints us with the theories, skills, and values that we teach. We believe a deeper understanding of Maslow will motivate and inspire the $\mathrm{OB}$ professor to find ways to explore and clarify his or her value foundation for leadership and teaching.

On a basic level, Maslow's work challenges us to reflect on our course objectives, the overall course design and choice of pedagogy, and ultimately the underlying values that we embrace and that guide our choices. Personal growth always involves self-confrontation. Am I going beyond a neutral, detached provider of theory and tools for managers to gain results? Am I helping students along a path of self-discovery and providing them positive visions and models of leadership? Is each and every topic and activity an opportunity to explore leadership and meaning? Where am I going through this class, through this course, through my teaching? Am I a real person involved in finding myself and humbly seeking deeper insights in every class? We need to continually seek opportunities for reflection and feedback to take better aim at the "inner target" of who we are (Herrigel, 1978).

In the long term, Maslow also challenges us to consider the wholeness of our lives, the contribution of our work, and the overall meaning of who we are. This self-confrontation puts us on the path of leadership by involving us in a slow, and sometimes painful, process of crafting pedagogical choices and action that align with and clarify our values and unique talents.

\section{References}

Adams, J. D. (1986). Achieving and maintaining personal peak performance. In Transforming leadership: from vision to results. Alexandria, VA: Miles River Press.

Alexander, C. N., Rainforth, M. V., \& Gelderloos, P. (1991). Transcendental Meditation, selfactualization, and psychological health: A conceptual overview and statistical meta-analysis. Journal of Social Behavior and Personality, 6, 189-247.

Bardoel, E. A., \& Haslett, T. (2006). Exploring ethical dilemmas using the "drifting goals" archetype. Journal of Management Education, 30, 134-148.

Bennis, W. (1989). On becoming a leader. New York: Addison-Wesley.

Bilimoria, D. (2000a). Management education's commitments to students. Journal of Management Education, 24, 422-423. 
Bilimoria, D. (2000b). Redoing management education's mission and methods. Journal of Management Education, 24, 161-166.

Bilimoria, D. (2000c). Teachers as learners: Whither our own development? Journal of Management Education, 24, 302-303.

Bolman, L. G. \& Deal, T. E. (2001). Leading with soul. San Francisco: Jossey-Bass.

Bowen, D. D. (1980). Experiential and traditional teaching of OB: A dubious distinction. Exchange: The Organizational Behavior Teaching Journal, 5, 7-12.

Boyatzis, R. E. (1994). Stimulating self-directed learning through the managerial assessment and development course. Journal of Management Education, 18, 304-323.

Boyatzis, R. E., \& McLeod, P. L. (2001). Our educational bottom line: Developing the whole person. Journal of Management Education, 25, 118-123.

Bradbury, H. (2003). Sustaining inner and outer worlds: A whole-systems approach to developing sustainable business practices in management. Journal of Management Education, 27, 172-187.

Brown, R. B. (2003). Emotions and behavior: Exercises in emotional intelligence. Journal of Management Education, 27, 122-134.

Cameron, K. S., Lussier, R. D., Ireland, R. N., New, R. J., \& Robbins, S. P. (2003). Management textbooks as propaganda. Journal of Management Education, 27, 711-729.

Daniels, D., Franz, R. S., \& Wong, K. (2000). A classroom with a worldview: Making spiritual assumptions explicit in management education. Journal of Management Education, 24, 540-561.

Deming, W. E. (2000). Out of the crisis. Cambridge, MA: MIT Press.

Drucker, P. F. (1999). Managing oneself. Harvard Business Review, 77, 64-74.

Drucker, P. F. (2002). They're not employees, they're people. Harvard Business Review, 80, 70-77.

Dupree, M. (1990). Leadership is an art. New York: Random House.

Ethics Education Task Force. (2004). Ethics education in business schools: Report of the Ethics Education Task Force to AACSB International's board of directors. Retrieved January 8, 2007, from http://www.aacsb.edu/Resource_Centers/EthicsEdu/EETF-report-6-25-04.pdf

Ferris, W. P. (2002). Gifting the organization. Journal of Management Education, 26, 717-731.

Gallos, J. V. (1996). On teaching and educating professionals. Journal of Management Education, 20, 294-297.

Goleman, D. (1997). Emotional intelligence: Why it can matter more that IQ. New York: Bantam. Herrigel, E. (1978). Zen and the art of archery. New York: Random House.

Hofstede, G. (1977). Cultures consequences: International differences in work related values. Beverly Hills, CA: Sage.

Hunt, J. M., \& Weintraub, J. R. (2004). Learning developmental coaching. Journal of Management Education, 28, 39-61.

International Commission on the Apostolate of Jesuit Education. (1986, December 8). The characteristics of Jesuit education. Retrieved January 8, 2007, from the Jesuit Education Web site: http://www.sjweb.info/education/doclist.cfm

Ivancevich, J., \& Matteson, M. (2002). Organizational behavior and management ( $6^{\text {th }}$ ed.). New York: McGraw-Hill/Irwin.

Jackson, K. T. (2006). Breaking down the barriers: Bringing initiatives and reality into business ethics education. Journal of Management Education, 30, 65-89.

Koltko-Rivera, M. E. (2006). Rediscovering the later version of Maslow's hierarchy of needs: Self-transcendence and opportunities for theory, research, and unification. Review of General Psychology, 10, 302-317.

Lund Dean, K., \& Beggs, J. M. (2006). University professors and teaching ethics: Conceptualizations and expectations. Journal of Management Education, 30, 15-44.

Maslow, A. H. (1943). A theory of motivation. Psychological Review, 50, 370-396.

Maslow, A. H. (1964). Religions, values, and peak-experiences. Columbus: Ohio State University Press. 
Maslow, A. H. (1965). Eupsychian management: A journal. Homewood, IL: Dorsey.

Maslow, A. H. (1971). The farther reaches of human nature. New York: Viking.

McGregor, D. (1960). The human side of enterprise. New York: McGraw Hill.

McShane, S., \& Von Glinow, M. (2005). Organizational behavior: Emerging realities for the workplace revolution (3rd ed.). New York: McGraw-Hill/Irwin.

Neal, J. A. (1997). Spirituality in management education: A guide to resources. Journal of Management Education, 27, 121-139.

O'Connor, D. J. (2001). The organizational behavior future search. Journal of Management Education, 25, 101-112.

O’Connor, D. J., \& Yballe, L. D. (2007). Team leadership: Critical steps to great projects. Journal of Management Education, 31, 292-312.

O’Neil, D. A., \& Hopkins, M. M. (2002). The teacher as coach approach: Pedagogical choices for management educators. Journal of Management Education, 26, 402-414.

Palmer, P. (1998). The courage to teach. San Francisco: Jossey-Bass.

Patzig, W. D., \& Zimmerman, D. K. (1985). Accuracy in management texts: Examples in reporting the works of Maslow, Taylor, and McGregor. The Organizational Behavior Teaching Review, 10, 1985-1986.

Pielstick, C. D. (2005). Teaching spiritual synchronicity in a business leadership class. Journal of Management Education, 29, 153-168.

Rynes, S. L., Quinn Trank, C., Lawson, A. M., \& Ilies, R. (2003). Behavioral coursework in business education: Growing evidence of a legitimacy crisis. Academy of Management Learning and Education, 2, 269-283.

Schein, E. H. (2004). Organizational culture and leadership. San Francisco: Jossey-Bass.

Schmidt-Wilk, J., Heaton, D. P., \& Steingard, D. (2000). Higher education for higher consciousness: Maharishi University of Management as a model for spirituality in management education. Journal of Management Education, 24, 580-611.

Schwartz, H. S. (1983). Maslow and the hierarchical enactment of organizational reality. Human Relations, 36, 933-956.

Senge, P. M. (1990). The fifth discipline: The art and practice of the learning organization. New York: Currency Doubleday.

Tischler, L. (2000). The growing interest in spirituality in business: A long-term socio-economic explanation. In G. Biberman \& M. Whitty (Eds.), Work and spirit: A reader of new spiritual paradigms for organizations. Scranton, PA: University of Scranton Press.

Vaill, P. (1989). Managing as a performing art. San Francisco: Jossey-Bass.

Walton, M. (1988). The Deming management method: The complete guide to quality management. New York: Perigree.

Wilber, K. (1996). Up from eden. Adyar, India: Theosophical Publishing.

Yballe, L. D., \& O'Connor, D. J. (2000). Appreciative pedagogy: Constructing positive models for learning. Journal of Management Education, 24, 474-483.

Yballe, L. D., \& O'Connor, D. J. (2004). Toward a pedagogy of appreciation. In D. Cooperrider $\&$ M. Avital (Eds.), Advances in appreciative inquiry: Constructive discourse and human organization (pp. 171-192). New York: Elsevier Science. 